Boise State University

ScholarWorks

Public Policy and Administration Faculty

Publications and Presentations

Department of Public Policy and Administration

$1-2020$

\title{
Balancing Multi-Level Politics in Local Environmental Policy Choices
}

Luke Fowler

Boise State University

Geoffrey Rabinowitz

Valdosta State University 
This is an author-produced, peer-reviewed version of this article. The final, definitive version of this document can be found online at Public

Works Management \& Policy, published by SAGE. Copyright restrictions may apply. doi: 10.1177/1087724X19834563

\title{
Balancing Multi-Level Politics in Local Environmental Policy Choices
}

\author{
Luke Fowler \\ Associate Professor \& MPA Director \\ School of Public Service \\ Boise State University \\ Geoffrey Rabinowitz \\ Doctoral Student \\ Department of Political Science \& Public Administration \\ Valdosta State Univeristy
}

Ambiguity shaped by politics and policy significantly influences the ability of local governments to manage environmental concerns. More specifically, environmental policies require policymakers to both satisfy political preferences and manage intergovernmental conflict while addressing environmental problems that are not limited to their jurisdictions. Given the volatility and dynamics of interactions between federal, state and local governments, more inventive and impactful policy tools are needed to create the environmental outcomes desired by local populations. However, local government positions in the federal system forces them to consider multi-level politics when making policy choices. Consequently, scholarship on local policy innovation indicates that policy choices are in response to both competitive pressures from other local governments and shortcomings in policy leadership at stateor federal-levels (Shipan and Volden, 2008, 2012; Gore, 2010; Jordan and Huitema, 2014). However, extant scholarship does little to differentiate these mechanisms across policy types or explain when local (i.e., localities synonymous with local governments) or supra-local (i.e., geographic areas that surround localities and include other governmental entities) politics becomes a predominant force. To this end, we argue that when making policy choices, local policymakers balance local and supra-local influences by exploiting uncertainty in policy goals and associated target populations. Stated more directly, local governments employ specific policy tools that take advantage of ambiguity in order to navigate the complex politics of the federal system.

We use air policy initiatives to examine these issues, where local governments are increasingly innovative with diverse policy tools (Woods and Potoski, 2010; Fowler, 2016). Although not all local governments engage in air policymaking, this group provides a means to quantitatively measure how political patterns influence policy choices. After reviewing literature on policy ambiguity, we examine how goal and target population ambiguity fluctuates across six common local air policy tools. Then, we test effects of local and supra-local politics on local policy choices with probit models. Consequently, we identify four scenarios based on ambiguity surrounding goals and target populations: 1) pollution prevention and regional cooperation initiatives affected by local politics; 2) outreach initiatives affected by supra-local politics; 3) transportation alternatives initiatives affected by both local and supra-local politics; and, 4) energy alternatives and smart growth initiatives affected by interactions between local and supra-local politics. Conclusions suggest ambiguity frames environmental policies, which is to local policymakers' advantage when balancing contentious multi-level politics.

\section{Ambiguity, Goals, and Target Populations}

Although typically viewed in a negative light, policy ambiguity can be a powerful policymaking tool. If policies are clear, actors mobilize to defend existing patterns that work to their benefit; however, if ambiguous, actors interpret policy in different ways, which may reduce conflict and lead to agreement, compromise, or coalition building (Matland, 1995; Jenkins-Smith, Nohrstedt, Weible, and Sabatier, 2014; Zahariadis, 2014; Davis and Stazyk, 2015). While policy ambiguity occurs along many dimensions, we focus here on two dimensions (policy goals and target populations) as influencing how local policymakers consider influences from local or supra-local political actors when making policy choices. We use the term supra-local to refer to political forces operating in a policy arena external to localities, but with some influence on local policy choices. More precisely, these supra-local arenas are geographically adjacent to or surround local areas and include political, social, or cultural similarities that aggregate from local areas, as well as political actors that are not bound to the localities making policy choices. 
This is an author-produced, peer-reviewed version of this article. The final, definitive version of this document can be found online at Public Works Management \& Policy, published by SAGE. Copyright restrictions may apply. doi: 10.1177/1087724X19834563

In the United States, the most obvious example are states, as local areas fall within their boundaries and tend to share similarities with surrounding political entities. Additionally, states create a discrete institutional barrier to the exercise of political power and political actors within that barrier tend to have an interest in policymaking by surrounding governmental units. However, supra-local may also include political actors at the regional- or national-levels. For example, local water policies may be influenced by politics across an entire watershed that includes multiple states. Although our focus here is on the U.S. and a policy that is easily situated within a state-local framework, the broader definition of supra-local is important as it applies to policies that rely on regional governance (e.g., climate change) or in nations without intermediate governmental units between national and local (e.g., United Kingdom).

First, policy goals require a balancing act between political support and policy management. While ambiguous goals allow actors to frame policy in order to appeal to broad coalitions, they may be too vague to allow for effective implementation (Chun and Rainey, 2005a, 2005b; Lee, Rainey, and Chun, 2009; Stazyk and Goerdel, 2011; JenkinsSmith, et al., 2014; Davis and Stazyk, 2015; Rainey and Jung, 2015). Consequently, there is a fine line between helpful and harmful ambiguity, where too little creates unaccommodating political environments that limit resources and support for organizational goals, while too much can contribute to failures that also lead to contractions in resources or support (Davis and Stazyk, 2015). As such, policymakers must frame policy goals in a way that strikes a balance between goals that can be achieved and those vague enough to limit conflicts.

To this end, low ambiguity goals are clearly defined (either explicitly or implicitly) and result in predictable local outputs and outcomes. These policies tend to include tried and tested policy tools that are well-understood in terms of effectiveness, externalities, and impacts. On the other hand, high ambiguity goals are unclearly defined via contrasting explicit or implicit policy statements that are interpreted differently across groups (e.g., dog-whistle politics) and result in unpredictable outputs or outcomes at either local or supra-local levels (Chun and Rainey, 2005b; Goodin and Saward, 2005). These local policies tend to include new or experimental policy tools, symbolic actions, or policies disguised to avert controversy. When ambiguous, external policy actors may perceive policy goals as important at the supra-local level (e.g., state), which may cause them to mobilize. Importantly, supra-local political actors without direct recourses through local elections or authority (e.g., neighboring communities) may seek to influence local policy choices through supra-local institutions (i.e., state legislatures) if local policymakers are unresponsive to their concerns. As such, the threat of state intervention (e.g. preemption) in itself is likely enough to cause local policymakers to be cognizant of supra-local interests.

Second, target populations frame constituencies. As such, "how we characterize groups of individuals is based on multiple perspectives of the problem, as well as symbolism and the strategic framing of interests" (Smith and Larimer, 2009, p. 193). Socially constructed target populations both determine how policymakers distribute costs and benefits to groups, and how political coalitions perceive these distributions. Here, ambiguity arises from the fluid nature of some groups, with different types of target populations drawing different political interests into policy debates. Consequently, some policies create political interests that are extensive, contentious, and developed, while others do not (Lowi, 1972; May, 1991; Anderson, 1997; Schneider, Ingram, and deLeon, 2014). More specifically, low ambiguity target populations include discrete groups of actors that can be defined, isolated from the general public, and are stable in membership over time (e.g., permitted pollutant dischargers). These target populations tend to include rigorous barriers to membership that create special, distinct target populations that are known quantities when formulating policy, which leads to limited but integrated policy networks (May, 1991; Jenkins-Smith, et al., 2014; Zahariadis, 2014). With unambiguous target populations, local policies are focused on populations who are clearly identified as locally bound, which draws little interest from supra-local political actors.

Conversely, high ambiguity target populations include volatile groups of actors that cannot be easily defined or isolated from the general public, and are fluid in membership over time (e.g., pedestrians). These target populations tend to include no rigorous (if any) barrier to membership, do not otherwise create special or distinctive populations, are an unknown quantity when formulating policy, and attract a broad but unintegrated policy network comprised of both local and supra-local actors (May, 1991). With ambiguous target populations, supra-local political actors are likely to become interested in policy decisions in order to protect their interests that may be affected, and in doing so, force local policymakers to consider supra-local politics. Consequently, both local and supra-local political actors play a role in influencing local policy choices, depending on how they may interpret the implications of policies. In other words, if policies are local, then local actors will influence policy choices, but if policies have implications at the supra-local level, then supra-local actors may also influence choices. 
This is an author-produced, peer-reviewed version of this article. The final, definitive version of this document can be found online at Public Works Management \& Policy, published by SAGE. Copyright restrictions may apply. doi: 10.1177/1087724X19834563

\section{Ambiguity and Local Air Policies}

\section{$\underline{\text { Institutional and Political Context }}$}

Local air initiatives offer a compelling case to examine local environmental policy choices, as diverse policy tools are employed by local agencies that are in unique positions to be influenced by both state and local politics. Under the U.S. Clean Air Act (CAA), the U.S. Environmental Protection Agency (EPA) sets broad air quality standards and provides program oversight, while states develop implementation plans and manage day-to-day operations (Belden, 2001; Fowler, 2016, 2018). On the other hand, local government roles are much more fluid than their state and federal counterparts and are largely defined either specifically by CAA State Implementation Plans (SIPs), or by broader state-local relationships (i.e., Dillon's rule versus Home rule) (Lester and Lombard, 1998; Woods and Potoski, 2010; Fowler, 2016, 2018). When not preempted, local air agencies are largely responsive to state programs, with state environmental expenditures, administrative centralization, and institutional capacity as key predictors of their existence. However, some argue that local air programs are an attempt to increase competitiveness between and within metropolitan areas by offering public health and environmental amenity benefits, in response to public environmental attitudes (Woods and Potoski, 2010; Fowler, 2016, 2018).

Furthermore, previous scholarship links political factors, such as partisanship and ideology, with local policy preferences in general as well as with environmental and air policy choices, specifically (Walker, 2006; Woods and Potoski, 2010; Gerber and Hopkins, 2011; Lee and Koski, 2015; Fowler, 2016, 2018). In most cases, these studies consistently find that Democratic and/or liberal cities are more innovative and progressive than Republican and/or conservative cities. Additionally, Riverstone-Newell (2012) finds that state preemption of local policies is most likely to occur when conflicts emerge between conservative state and progressive local leadership. Importantly, partisan divisions are widening in environmental policy, with Democrats becoming more pro-environment and Republican becoming less so, which further suggests differences in policy choices are likely to emerge in increasingly polarized local policy arenas (Dunlap and McCright, 2008; Daniels, Krosnick, Tichy, and Tompson 2013). Consequently, we believe local partisanship to be a key factor in understanding local political patterns associated with interpreting ambiguous environmental policies. As such, we expect areas that are more conservative to be less likely to have local air policies, as they will be more likely to elect Republican candidates to office at local, state, and federal-levels and more opposed to environmental policy innovations. However, we also expect local and state-level political leanings to have differential effects across policy types.

\section{$\underline{\text { Local Air Initiatives }}$}

Previous assessments of local air initiatives indicate six categories in common use: 1) pollution prevention; 2) outreach and communication; 3) regional cooperation; 4) smart growth; 5) transportation alternatives; and 6) energy alternatives (NALGEP, 2016; Fowler, 2016). Table 1 provides brief descriptions, examples, percentages of city and county agencies using each type, and applicable policy types. City and county air agencies surveyed for this study reported pollution prevention (73.8\%), outreach (83.3\%), and regional cooperation (88.1\%) are the most popular initiative categories, while smart growth (38.1\%), transportation alternatives (40.5\%), or energy alternative (38.1\%) initiatives are least popular. Additionally, respondents reported using multiple initiatives types with $88.1 \%$ reporting using two or more initiative categories, and 52.4\% reporting four or more initiative categories. Interestingly, of local agencies operating four or more types, all operate pollution prevention, regional cooperation, and outreach initiatives. On the other hand, of those operating less than two types, $90.0 \%$ operate at least one of those types and $72.2 \%$ are operating two. Importantly, as we analyze how ambiguity affects these policy initiatives, we define ambiguity as it relates to local versus supra-local, with low ambiguity suggesting issues clearly connect to or are limited to local areas and high ambiguity suggesting issues may be unclear in their implications for local and/or supra-local areas. In other words, our focus is whether policy implications can be framed as local or supra-local.

\section{[Table 1 about here]}

First, pollution prevention policies that correspond to state management strategies or regional cooperation initiatives that align inter-local policies create specific outcomes for cities but also contribute to existing goals managed at stateor regional-levels. Localities use pollution prevention and regional cooperation initiatives to improve local environmental conditions by aligning their policies with established supra-local efforts, in order to better meet citizen preferences. These policies integrate local efforts with existing efforts from other organizations and rely on identified purposes and externalities, which create clearly defined actions and outcomes that contribute to supra-local 
This is an author-produced, peer-reviewed version of this article. The final, definitive version of this document can be found online at Public Works Management \& Policy, published by SAGE. Copyright restrictions may apply. doi: 10.1177/1087724X19834563

environmental goals. Additionally, these policies focus on stationary pollution sources and/or local public agencies, creating discrete target populations. For example, in an interview with a local newspaper, a Shelby County (Tennessee) representative emphasized environmental health services' success in overseeing air quality permits as part of a state-led management strategy, and contended: "It's a good time to be living and breathing in Shelby County" (Charlier, 2017). This suggests the department views air quality permitting (i.e., pollution prevention) and cooperation with the state as key to improving local air, which in turn makes the local area a more attractive place to live.

For these policies, low ambiguity isolates political conflict with clarity around who is affected and how they will be affected. As such, the principal policy debate occurs within local political circles, and is largely influenced by how political actors view local environmental responsibilities. Nevertheless, local governments must ensure both goals and target populations fall within their jurisdictions; otherwise, they risk intervention from state or federal authorities. From local perspectives, these policies are limited in scope and create positive discernible impact on local environmental conditions, even though they contribute to supra-local environmental goals. Since these policies do not directly affect environmental outcomes or efforts in other jurisdictions, they do not bleed into political spheres of supra-local interests, diminishing influences from state- or regional-level politics. However, local conservative political interests may still oppose these policies based on their environmental attitudes or beliefs. Hence, local politics drives these policies, with conservative-leaning areas being less supportive of environmental policy innovations. Consequently, local areas that are more conservative are less likely to use pollution prevention or regional cooperation initiatives, as local political perspectives are more opposed to progressive environmental policies.

Hypothesis 1: Likelihood of localities using pollution prevention initiatives will decrease as local areas become more conservative.

Hypothesis 2: Likelihood of localities using regional cooperation initiatives will decrease as local areas become more conservative.

Second, outreach programs are directed at educating publics as an experiment in determining how supra-local interests will react to challenges to existing status quos, creating very fluid (ambiguous) target populations and ambiguous goals. Localities use outreach to create spotlights where other organizations are deficient without committing themselves to specific policy goals. As such, these policies create an experiment by challenging supra-local actors on environmental policies. For example, Austin (Texas) created an online environmental dashboard to track data on their sustainability efforts, with the explicit goal of "leadership" stated several times (Austin, 2016). This indicates that the city puts substantial effort into highlighting policies as symbols of best practices, and to encourage other organizations to follow their "lead." High degrees of ambiguity in both goals and target populations allow localities to focus on politics, without burdening themselves with effective policy management. Since there is no clear delineation of who these policies affect or what goals they will achieve, neither jurisdictions nor authorities create limitations. These policies are broad in scope and only serve to "challenge" other political actors (e.g., neighboring communities, state legislatures) or symbolize needed actions. As such, these policies are likely to draw ire from conservative state leadership who may be pursuing a political agenda that is unsupportive of environmentalism.

Since these policies are aimed at influencing external interests, state or regional politics affects these policies, with localities gambling on whether supra-local political climates are responsive to such challenges. In other words, local leaders may be unwilling to make an investment in outreach programs if they think the programs will go unnoticed by political actors in surrounding regions. However, state political interests do not directly play roles in these local policy choices, rather policymakers are acting in anticipation of how state leaders will react to symbolic actions. Conversely, with no direct local outcomes, local politics is not a predominant force and local political interests are unlikely to mobilize. As such, these policies are driven by supra-local politics with focus on stimulating action in external interests. Consequently, localities in more conservative states are less likely to use outreach initiatives, as state leaders will be less likely to respond positively to a push for more environmental focus in policymaking.

Hypothesis 3: Likelihood of localities using outreach initiatives will decrease as states become more conservative.

Third, transportation alternatives develop environmental quality by focusing on changes in local and supra-local behaviors that will contribute to improved local conditions. Here, localities target fluid groups that stretch beyond their jurisdiction for behavioral changes that create clear benefits to their citizens. For example, in a resolution, the Kansas City's (Missouri) City Council frames a "no idling zone" as "idling vehicles contribute significantly to air pollution... which adversely affect Kansas City citizens... it is in the public interest that Kansas City motorists reduce 
This is an author-produced, peer-reviewed version of this article. The final, definitive version of this document can be found online at Public Works Management \& Policy, published by SAGE. Copyright restrictions may apply. doi: 10.1177/1087724X19834563

fuel consumption and resulting vehicle emissions” (Kansas City, 2017). The resolution refers to citizens early on, but to motorists when specifying behavioral changes, with an estimated 102,000 non-residents (equal to $23.1 \%$ of city population) commuting into Kansas City daily (MERIC, 2017). This connects fluid target populations that includes non-residents to goals for Kansas City's citizens. While anti-idling regulations are typically aimed at heavy commercial vehicles (i.e., tractor-trailers), statutory language is vague enough to create ambiguity surrounding exactly whom will be affected.

While unambiguous goals identify how target populations will be affected, ambiguous target populations make it unclear who will be affected. While clearly defined goals fall within local jurisdictions, achieving these goals requires supra-local target populations that may be more conservative than local populations. Since citizens of potentially any area can be affected by traveling to localities, these policies require local policymakers to consider whether citizens beyond local areas are likely to comply with policies and/or if they are likely to avoid areas due to policies. Furthermore, as states become more conservative and the political environment is less in favor of progressive policies, localities face greater risk of states attempting to intervene in their local policy processes (e.g., preemption). As such, policymakers gamble on whether state or regional populations will respond positively to policy choices, and try to match policies with preferences of both local and supra-local political populations. This creates particularly difficult challenges when local areas are more progressive than their surrounding regions. Therefore, these policies are driven by both local and supra-local policy preferences as they impact both local conditions and populations that stretch across the region. Local areas that are more conservative or those in states that are more conservative are less likely to use transportation alternative initiatives.

Hypothesis 4: Likelihood of localities using transportation alternative initiatives will decrease as both local areas and states become more conservative.

Finally, energy alternatives and smart growth policies contribute local efforts to large-scale environmental issues without specific indications of where policies contribute to local outcomes or integrate with larger unintegrated strategies. While these policies focus on altering behaviors of local target populations, complex environmental problems make it difficult to determine impacts at either local or supra-local levels. Additionally, these problems can lack coordinated strategies or central authority, making it difficult to integrate local and supra-local efforts. With energy alternative or smart growth initiatives, discrete target populations take on burdens in retrofitting existing or constructing new buildings with energy and sustainability concerns in mind in order to achieve supra-local goals with unclear implications at local or supra-local levels. For example, a resolution from the El Paso (Texas) City Council affirms the city's "dedicat[ion] to attaining clean air and reasonably-priced electric energy" (El Paso, 2017). The resolution grounds policy in clean air with broad assumptions that changes in energy consumption reduces pollutant emissions, creating an indirect relationship between policy and local outcomes. Additionally, the resolution ties local changes to larger energy goals outside local jurisdictions without clear plans to integrate these efforts with those of other organizations. This suggests that localities use policies knowing that micro-level behaviors contribute to macrolevel outcomes, even when they cannot connect the two within their limited policy arena.

While unambiguous target populations identify who will be affected, ambiguous policy goals make outcomes (intended or actual) unclear. As such, policies may address issues that are "debatably" beyond local authority or too large in scale to be managed unilaterally, which likely draws the attention from conservative leaders both locally and regionally. Consequently, local policymakers gamble on contributions from other organizations, creating dilemmas where local governments may take on costs but share benefits (Helm, 2010). Costs may be well worth it if policymakers expect other organizations to follow suit, with discernible large-scale changes resulting over time. However, if policymakers do not expect other organizations to follow suit, they may be unwilling to take on costs and provide opportunities for free-riders. Consequently, even progressive local leaders may be hesitant to pursue these policies in conservative states. Further, supra-local politics moderates local perceptions of costs, benefits, or risks as localities weigh potential repercussions of these policies. Although both state and local areas that are more conservative are less likely to use these policies, local area conservativism likely mitigates state-level influence, causing an interaction between state-level and local-level conservativism in determining the likelihood of local use of energy alternatives or smart growth initiatives.

Hypothesis 5: Likelihood of localities using energy alternative initiatives will decrease as states become more conservative, but conservatism in local areas will mitigate this. 
This is an author-produced, peer-reviewed version of this article. The final, definitive version of this document can be found online at Public Works Management \& Policy, published by SAGE. Copyright restrictions may apply. doi: 10.1177/1087724X19834563

Hypothesis 6: Likelihood of localities using smart growth initiatives will decrease as states become more conservative, but conservatism in local areas will mitigate this.

\section{Methods}

We use probit models to examine local policy choices, with coefficients reported. While additive models sufficiently test direct effects, we use interaction terms to test interactions of local and supra-local politics (Friedrich 1982; Travis and Zahariadis 2002). Since interaction terms can produce inflated standard errors and initial tests indicated heteroscedasticity, we use robust standard errors (Beck and Katz, 1995a, 1995b). Further diagnostics indicated this step corrected the issue, and there were no other assumption violations (Chatterjee and Hadi 2006). For each dependent variable, we present four models: local politics, state politics, local and state politics, and interactive local and state politics. We use McFadden's pseudo- $\mathrm{R}^{2}$ and Akaike information criterion (AIC) to compare models (Menard, 2002).

Using a two-step process, we collected data on 42 city and county air agencies in two years over a four-year period (2012 and 2016), creating a dataset of 84. First, data was collected via survey of local government members of the National Association of Clean Air Agencies (NACAA). NACAA members: 1) are the most accurate list of local-level air agencies; 2) have dedicated missions to air quality; 3) are implementing initiatives for air improvement; and, 4) are engaged in air policymaking (Fowler, 2016, 2018). While this creates a unique sample which accurately reflects local air agencies, there are limitations to generalizability of findings as not all local governments engage in air policymaking. We originally contacted 117 local-level members listed in NACAA's online membership directory three times via mail and email, with a response rate of 68.6\% (81 total responses) (NACAA, 2017). However, NACAA membership is $42.7 \%$ regional agencies (e.g., regional planning, multi-county health districts), which operate differently than city and county agencies (Fowler, 2016, 2018). Most importantly, regional agencies have narrowly focused missions and a high degree of independence from locally elected officials, while city and county agencies are units of general mission governments under direct supervision of locally elected officials, creating different contexts for policy choices. Therefore, we focus our analysis on 67 city and county agencies (57.3\% of NACAA membership), of which 42 responded, resulting in a response rate of $62.7 \%$.

Based on descriptive statistics, respondents represent city and county air agencies and NACAA members, with response distributions similar to all respondents. NACAA city and county members represent 23 states, with $20.9 \%$ from the West region, $41.8 \%$ from the South, $7.5 \%$ from the Northeast, and 28.3\% from the Midwest. In comparison, survey respondents represent 19 states, with $19.0 \%$ from the West, $40.5 \%$ from the South, $9.5 \%$ from the Northeast, and $31.0 \%$ from the Midwest. Additionally, respondents report a range of agency sizes. For employees, $40.5 \%$ report less than 10,11.9\% between 11 and 20, 23.8\% between 21 and 40, and 23.8\% over 40 . For budgets, 37.8\% report less $\$ 1$ million, $35.1 \%$ between $\$ 1$ and 3 million, $13.5 \%$ between $\$ 3$ and 7 million, and $13.5 \%$ over $\$ 7$ million. Finally, $23.8 \%$ of respondents report direct report relationships to elected officials (e.g., county board or mayor), $21.4 \%$ to senior executives (e.g., city manager or deputy manager), and 54.8\% to department directors.

Second, we use city and county websites to confirm survey results and determine if/what air policy changes occurred between 2012 and 2016. Searches of city and county council resolutions and air agency websites confirms policy types used by agencies. Additionally, since survey data prior to 2016 was not available, reviewing council resolutions and agency websites provided additional data on policy changes that occurred during the study timeframe. While some specific policy changes occurred or additional policies adopted, there was no evidence that general mixtures of policy types used by local agencies in the sample changed between 2012 and 2016 or that any specific policies adopted during that time were first of their kind for that local agency. For the most part, almost all policy changes were extensions or updates of existing programs. Consequently, the two-step data collection process indicates our data is an accurate depiction of local air policies during this time period.

We use 2012 and 2016 as the two most recent Presidential election years, to capture comparable political patterns across state- and local-levels. Additionally, using multiple years, reduces potential bias created within single election years. While we cannot pinpoint exact timing of all policy choices related to programs, we assume local policymaking is responsive to the political environment. As such, local leadership likely considered which policy types were utilized during the political context of these two Presidential elections, allowing us to determine any correlation between policy types and partisanship. Additionally, the 2012 and 2016 elections were both highly contested and politically 
This is an author-produced, peer-reviewed version of this article. The final, definitive version of this document can be found online at Public Works Management \& Policy, published by SAGE. Copyright restrictions may apply. doi: 10.1177/1087724X19834563

polarizing, involving both Democratic and Republican victories and four political candidates representing two major parties. Therefore, these two elections together capture political patterns at state- and local-levels that could otherwise be masked within single elections.

\section{Dependent Variable}

We use nominal dependent variables comparing local agencies with and without each of six categories of air initiatives. Survey respondents were asked: "does your office manage initiatives that fall into any of the following categories?” with each initiative category listed, along with brief descriptions (see Table 1). We coded dependent variables so that probit models indicate probability of local agencies using each category of initiative. Table 2 displays variable descriptive statistics.

\section{[Table 2 about here]}

\section{Predictor Variables}

To measure conservativism at local and supra-local levels, we use state and local partisan voting. Although supralocal politics are not limited to any specific jurisdictional level, states form a key political boundary within the U.S. as they encompass both a geographical area and a governmental unit that create discrete institutional barriers for political power. As such, state-level political variables provide a good point of comparison between supra-local and local political patterns, as state politics aggregates from local areas and includes political actors that may seek to influence local policy choices. Furthermore, scholars connect partisan voting to general political patterns that affect policymaking, and it creates an objective comparison point between both local and supra-local in the same geographic area to those in different geographic areas (Cohen, 2006; Gerber, Huber, and Washington, 2010). Additionally, partisan division in environmental policy tends to occur along ideological lines, so voting patterns makes for a good approximation of environmental attitudes of local electorates (Daniels, et al., 2013).

We measure state and local partisanship with percentage Republican vote for President, using data from respective state elections offices. There is a strong positive correlation (.395) between state and local Republican vote for President. However, local voting shows a wider range (14.0\% to $70.2 \%)$ of Republican support than state voting (33.9\% to 62.1\%) and, on average, local voting (42.0\%) is less supportive of Republicans than state voting (50.7\%). Additionally, state-local partisan mix is as expected with fairly even distribution of matched state-local partisan preferences (29.8\% for Democrat-Democrat, and 23.8\% for Republican-Republican), but uneven distribution of mismatched state-local partisan preferences (40.5\% for Republican-Democrat, and 6.0\% for Democrat-Republican). Given national trends in partisan voting in urban areas and the urban focus of air agencies (Gerber and Hopkins, 2011; Hajnal and Trounstine, 2014), our data reflects national patterns surrounding local air agencies.

We use seven other variables to control for state environmental efforts, local competition, local authority, air quality, and socio-economic differences. First, we control for others factors related to state environmental efforts and local competition that may influence local policy choices. We measure state environmental effort as state environmental spending per capita (in thousands of dollars per person) (Census, 2017). Additionally, we measure local competition and bureaucratic capacity as population within agency jurisdictions (in millions of people) and multi-agency areas, which compares metropolitan areas with and without (base category) multiple local air agencies. Second, as not all local agencies have the same authorities, we control for differences. Based on Woods and Potoski (2010), we use three survey items to determine whether local agencies have authority to: 1) set criteria pollutant ambient air standards; 2) set new source performance standards; or, 3) set hazardous air pollutant standards. We, then, use a count variable measuring number of authorities.

Third, we control for socioeconomic differences with per capita personal income (in thousands of dollars per person). Additionally, we use personal income from manufacturing, transportation, and utilities industries (in thousands of dollars per person) to control for economic activity from primary sources of air pollutant emissions (BEA, 2017). Finally, to control for differences in air quality, we measure annual median air quality index (AQI) for monitoring sites associated with each local agency (EPA, 2017). AQI creates standardized measurement of pollutant concentrations measured on a scale of 0 to 500, and makes direct comparisons across NAAQS criteria pollutants and air quality monitoring sites (EPA, 2017b). 
This is an author-produced, peer-reviewed version of this article. The final, definitive version of this document can be found online at Public

Works Management \& Policy, published by SAGE. Copyright restrictions may apply. doi: 10.1177/1087724X19834563

\section{Results}

Table 3 displays probit model results for pollution prevention and regional cooperation initiatives; Table 4, for smart growth and energy alternative initiatives; and, Table 5, for transportation alternatives and outreach initiatives. First, findings for pollution prevention and regional cooperation indicate these policies are influenced by local political patterns, with a negative coefficient for local Republican vote as the only statistically significant political indicator. As local Republican vote increases (i.e., local areas become more conservative), local agencies are less likely to use pollution prevention and regional cooperation policies. Additionally, pseudo- $\mathrm{R}^{2}$ indicates P.2 and R.2 are significant improvements over P.1 and R.1, while P.3, P.4, R.3 and R.4 only offer marginal improvements over P.2 and R.2. Furthermore, AIC indicates P.2 and R.2 are superior to other models. Consequently, there is support for hypotheses 1 and 2 concerning the relationship between local conservatism and pollution prevention and regional cooperation initiatives.

\section{[Tables 3, 4, and 5 about here]}

Second, findings for outreach initiatives indicate these policies are influenced by supra-local political patterns, with a negative coefficient for state Republican vote as the only statistically significant political indicator. As state Republican vote increases (i.e., states become more conservative), localities are less likely to use outreach programs. Additionally, pseudo- $\mathrm{R}^{2}$ indicates $\mathrm{O} .1$ is a significant improvement over $\mathrm{O} .2$, while $\mathrm{O} .3$ and $\mathrm{O} .4$ are only marginally better than O.1. Furthermore, AIC indicates O.1 is superior to others. As such, there is support for hypothesis 3 concerning the relationship between state conservatism and outreach initiatives.

Third, findings for transportation alternatives indicate these policies are influenced by both local and supra-local political patterns, where negative coefficients for both state and local Republican vote are statistically significant. As Republican vote at both local- and state- levels increases, localities are less likely to use transportation alternatives initiatives. However, findings for state vote in T.3 are only statistically significant at the 0.1 level, so they may be less reliable than other findings presented here. Additionally, pseudo- $\mathrm{R}^{2}$ indicates T.3 is a significant improvement over both T.1 and T.2, while T.4 is only marginally better than T.3. Furthermore, AIC indicates T.3 is superior to other models, but only marginally so compared to T.2. Consequently, there is some support for hypothesis 4 concerning the relationship between state and local conservatism and transportation alternatives, but findings for state vote in model T.3 create a limitation to their generalizability.

Finally, findings for smart growth and energy alternatives indicate these policies are influenced by an interaction between local and supra-local political patterns. For additive models, only local Republican vote is significant in S.2, E.2, and E.3. However, for both S.4 and E.4, state and local Republican vote and interaction terms are statistically significant. Additionally, pseudo- $\mathrm{R}^{2}$ indicates significant improvements over additive models, including $29.5 \%$ and 25.6\% increases, respectively. Furthermore, AIC indicates S.4 and E.4 are superior to other models. In Appendix A, Figures S.1 and E.2 graph interactive effects for probability of smart growth initiatives and energy alternatives for state and local Republican vote values at approximately 25th, 50th, and 75th percentiles, respectively. For smart growth initiatives, local vote in low Republican vote states has only marginal effects, but distinctive effects in high Republican vote states. While probability is only marginally different for low Republican vote (35\%) localities between low (47\%) and high Republican vote (57\%) states, probability decreases sharply for high Republican vote (49\%) localities as state Republican vote increases.

For energy alternative initiatives, local vote in high Republican vote states has only marginal effects, but distinctive effects in low Republican vote states. While probability is only marginally different for high Republican vote localities between low and high Republican vote states, probability decreases sharply for low Republican vote localities as state Republican vote increases. Interestingly, both interactions indicate that as state Republican vote increases probability of smart growth and energy alternative policies decrease. However, effects are different between the two policies, with high Republican vote localities affected for smart growth initiatives and low Republican vote localities for energy alternatives. Therefore, these findings support hypotheses 5 and 6 concerning the role of local conservatism in mitigating state conservatism and the corresponding impacts on smart growth and energy alternative initiatives. Finally, additional findings indicate that other variables also affect local policy choices, and these vary widely between the six policy tools. Coefficients and statistical significance between models were fairly consistent, suggesting reliability of results. Pseudo- $R^{2}$ indicates all models are moderate to strong predictors of local policy choices. 
This is an author-produced, peer-reviewed version of this article. The final, definitive version of this document can be found online at Public Works Management \& Policy, published by SAGE. Copyright restrictions may apply. doi: 10.1177/1087724X19834563

\section{Conclusions}

Local governments are in delicate positions when choosing policy tools to address complex environmental policy problems within their limited jurisdictions, which leads to balancing local and supra-local politics. Although limited to a unique dataset of local agencies, findings support our six hypotheses concerning the relationship between policy types and levels of politics. When policies have unambiguous goals and target populations (i.e., pollution prevention or regional cooperation), policy arenas are narrowed to specified goals and target populations aligning with local authority and external political interests are unlikely to be a factor. However, when policies have ambiguous goals or target populations (i.e., transportation alternatives, energy alternatives, or smart growth), policy arenas are broadened and external political interests are drawn into the mix. Nevertheless, ambiguity in goals and target populations affect balances of local and supra-local policies differently. Transportation alternative policies appear to have a direct relationship with both local and supra-local politics, while smart growth and energy alternatives policies appear to be affected by interactions between the two. This likely results from partisan policy framing, intergovernmental cooperation for collective action problems, or polarization in state legislatures (Feiock and Scholtz, 2009; Fletcher, 2009; Shor and McCarty, 2011). However, findings presented here do not offer enough specificity to confirm those assertions. Finally, when ambiguity in goals and target populations define whole policies (i.e., outreach), supra-local politics is a driving force, as policies become symbols and elicit responses from external interests.

These findings have two important implications for environmental policy and local governance. First, in multi-level systems, politics impacts policy choices at different levels. Adding to previous findings of multi-level political influences in policy choices (Shipan and Volden, 2006), our findings indicate local policy innovations are functions of complex political contexts, where both local and supra-local politics impact policy choices. Since local governments do not function in vacuums, external political interests factor into internal choices with ambiguity expanding or contracting these influences (Shipan and Volden, 2005, 2008). With increasing partisan polarization, balancing multi-level politics will be more important to policymakers at all levels, especially in progressive cities attempting to address polarizing issues (e.g., climate change) in conservative states, or progressive states doing the same while national political institutions are controlled by conservatives. As such, additional research should explore how polarization between governmental levels influences environmental policy choices to provide better insights into how policymakers cope with contentious politics. Second, policymakers use ambiguity to their advantage to create policies that best meet their political challenges. As local air policy indicates, there are multiple tools available to address similar issues, but not all policy choices align with prevailing political climates. This finding provides some insight into how local governments address policy challenges related to complex environmental issues, while balancing competing local and supra-local partisan perspectives.

Nevertheless, these findings have limitations by considering only two dimensions of ambiguity; although, there are numerous dimensions on which to classify it. While other parameters exist, goals and target populations are important aspects for balancing local and supra-local political interests in local policy choices. Additionally, common in empirical studies, operationalization and data of theoretical concepts create limitations. Our findings rely on specific measures capturing concepts, which may demonstrate certain flaws. Furthermore, while our statistical analyses fall within reported norms, small n-sizes can increase likelihood of type 1 errors and reduce statistical power (Menard, 2002; Vittinghoff and McCulloch, 2007). As such, our findings should be considered with caution when applying them to non-NACAA members or to local governments in general. Finally, alternative explanations may exist that better capture differences between initiatives, or that better explain how local and/or supra-local politics influence local policy choices. While both previous research and evidence justify our findings, we suggest future research apply this typology to other environmental policies, including those for emerging challenges, such as climate change, and more traditional challenges, such as water quality. Research should also explore specific mechanisms by which supralocal political interests become factors in local policy choices, and how local and supra-local politics interact. Balancing multi-level politics is a significant factor in local policy innovation for complex environmental issues, and ambiguity is a key tool in that balance to increase the likelihood of achieving desired outcomes. 
This is an author-produced, peer-reviewed version of this article. The final, definitive version of this document can be found online at Public Works Management \& Policy, published by SAGE. Copyright restrictions may apply. doi: 10.1177/1087724X19834563

\section{References}

Anderson, J. 1997. Governmental Suasion: Refocusing the Lowi Policy Typology. Policy Studies Journal 25(2): 266-82.

Austin [Texas]. 2017. Sustainability Framework. https://data.austintexas.gov/stories /s/ Office -of-SustainabilityDashboard/5t5d-xrry/ [Retrieved June 1, 2017].

Beck, N. and J.N. Katz. 1995a. Nuisance vs. Substance: Specifying and Estimating Time-Series-Cross-Section Models. Political Analysis 6(1): 1-36.

Beck, N. and J.N. Katz. 1995b. What to do (and not to do) with Time-Series-Cross-Section Data in Comparative Politics. American Political Science Review 89(3): 634-47.

Belden, R.S. 2001. The Clean Air Act. Chicago: American Bar Association, Section of Environment, Energy, and Resources.

Berry, F.S. and W.D. Berry. 2014. Innovation and Diffusion Models in Policy Research. In Theories of the Policy Process, $3^{\text {rd }}$ ed., edited by P.A. Sabatier and C.M. Weible, p. 307-359. Boulder, CO: Westview.

Chatterjee, S. and A.S. Hadi. 2006. Regression Analysis by Example. Hoboken, NJ: Wiley.

Charlier, T. 2017. Air Pollution down Sharply in Shelby County, so are Revenues. Commercial Appeal. www.commercialappeal.com/story/news/environment/2017/03/24/ air-pollution-down-sharply-shelbycounty-but-so-revenues/99547264/ [Retrieved June 1, 2017].

Chun, Y.H. and H.G. Rainey. 2005a. Goal Ambiguity in Organizational Performance in U.S. Federal Agencies. Journal of Public Administration Research \& Theory 15(4): 529-57.

Chun, Y.H. and H.G. Rainey. 2005b. Goal Ambiguity in U.S. Federal Agencies. Journal of Public Administration Research \& Theory 15(1): 1-30.

Cohen, J.E. 2006. Public Opinion in the State Politics. Stanford, CA: Stanford University.

Daniels, D. P., J. A. Krosnick, M. P. Tichy, and T. Tompson. 2013. Public Opinion on Environmental Policy in the United States. In Handbook of U.S. Environmental Policy, edited by M. Kraft, and S. Kamieniecki, 461-86. New York: Oxford University.

Davis, R.S. and E.C. Stazyk. 2015. Developing and Testing a New Goal Taxonomy: Accounting for the Complexity of Ambiguity and Political Support. Journal of Public Administration Research \& Theory 25(3): 751-775.

Dunlap, R.E. and McCright, A.M. 2008. A Widening Gap: Republican and Democratic Views on Climate Change. Environment: Science \& Policy for Sustainable Development 50: 26-35.

El Paso [Texas]. 2017. Resolution Adopting Texas Clean Air Cities Coalition. http://legacy. elpasotexas.gov/muni_clerk/agenda/10-31-06/10310612A.pdf [Retrieved June 1, 2017].

Feiock, R.C. and J.T. Scholtz. 2009. Self-Organizing Federalism. New York: Cambridge University.

Fletcher, A.L. 2009. Clearing the Air: The Contribution of Frame Analysis to Understanding Climate Policy in the United States. Environmental Politics 18(5): 800-16.

Fowler, L. 2016. Local Governments: The "Hidden Partners” of Air Quality Management. State \& Local Government Review 48(3): 175-88.

Fowler, L. 2018. When Needs Meets Opportunity: Expanding Local Air Networks. American Review of Public Administration 48(3): 219-231.

Friedrich, R.J. 1982. In Defense of Multiplicative Terms in Multiple Regression Equations. American Journal of Political Science 26(3): 797-833.

Gerber, A.S., G.A. Huber, and E. Washington. 2010. Party Affiliation, Partisanship, and Political Beliefs: A Field Experiment. American Political Science Review 104(4): 720-44.

Gerber, E.R. and D.J. Hopkins. 2011. When Mayors Matter: Estimating the Impact of Mayoral Partisanship on City Policy. American Journal of Political Science 55(2): 326-39.

Goodin, R.E. and M. Saward. 2005. Dog Whistles and Democratic Mandates. Political Quarterly 76(4): 471-76.

Gore, C.D. 2010. The Limits and Opportunities of Networks: Municipalities and Canadian Climate Change Policy. Review of Policy Research 27(1): 27-46.

Hajnal, Z. and J. Trounstine. 2014. What Underlies Urban Politics? Race, Class, Ideology, Partisanship, and the Urban Vote. Urban Affairs Review 50(1): 63-99.

Helm, D. 2010. Government Failure, Rent-Seeking, and Capture: The Design of Climate Change Policy. Oxford Review of Economic Policy 26(2): 182-196.

Jenkins-Smith, H., D. Nohrstedt, C. Weible, and P. Sabatier. 2014. The Advocacy Coalition Framework: Foundations, Evolution, and Ongoing Research. In Theories of the Policy Process,. edited by P.A. Sabatier and C.M. Weible, 267-306. Boulder, CO: Westview. 
This is an author-produced, peer-reviewed version of this article. The final, definitive version of this document can be found online at Public Works Management \& Policy, published by SAGE. Copyright restrictions may apply. doi: 10.1177/1087724X19834563

Jordan, A., and Huitema, D. 2014. Innovations in Climate Policy: The Politics of Invention, Diffusion, and Evaluation. Environmental Politics 23(5): 715-34.

Kansas City [Missouri]. 2017. Declaring the City Council’s Intent to Make Kansas City a "No Idling Zone.” http://cityclerk.kcmo.org/LiveWeb/Documents/Document.aspx?q=LMKig RQK\%2 fiO6KkOLH\%2fA7sOtYasvcyP910uImS3gkVrhFSs699j\%2bP9\%2brdYDmT \%2b206NOGbhRhlf5MC0\%2bh7l6q\%2fWw\%3d\%3d [Retrieved June 1, 2017].

Lee, T., and Koski, C. 2015. Multilevel Governance and Urban Climate Change Mitigation. Environment \& Planning C: Government \& Policy 33(6): 1501-17.

Lee, W.J., H.G. Rainey, and Y.H. Chun. 2009. Of Politics and Purpose: Political Salience and Goal Ambiguity of U.S. Federal Agencies. Public Administration 87(3): 457-84.

Lester, J.P. and E.N. Lombard. 1998. Environmental Regulation and State-Local Relations. In Governing Partners, edited by R.L. Hansen, 139-60. Boulder, CO: Westview.

Lowi, T.J. 1972. Four Systems of Policy, Politics, and Choice. Public Administration Review 32(4): 298-310.

Matland, R.E. 1995. Synthesizing the Implementation Literature: The Ambiguity-Conflict Model of Policy Implementation. Journal of Public Administration Research \& Theory 5(2): 145-74.

May, P.J. 1991. Reconsidering Policy Design: Policies and Publics. Journal of Public Policy 11(2): 187-206.

Menard, S. 2002. Applied Logistic Regression Analysis, $2^{\text {nd }}$ ed. Thousand Oaks, CA: Sage.

Missouri Economic Research and Information Center (MERIC). 2017. Daytime Population: Changes in Missouri Counties and Selected Cities. https://www.missourieconomy.org/pdfs/daytime_population.pdf [Retrieved February 1, 2017].

National Association of Clean Air Agencies (NACAA). 2017. Find a State or Local Agency. http://www.4cleanair.org/agencies [Retrieved February 1, 2017].

National Association of Local Government Environmental Professionals (NALGEP). 2017. Profiles of Local Clean Air Innovation. http://www.nalgep.org/uploads/pdf/publi14.pdf [Retrieved February 1, 2017].

National Association of Counties (NAC). 2017. Air Quality Improvement. http://www.naco.org/ sites/default/files/documents/AQ_Factsheet\%20-\%20Air\%20Quality\%20Improvement \%20Guide\%20for\%20Local\%20Governments.pdf [Retrieved February 1, 2017].

Rainey, H.G. and C.S. Jung. 2015. A Conceptual Framework for Analysis of Goal Ambiguity in Public Organizations. Journal of Public Administration Research \& Theory 25(1): 71-99.

Riverstone-Newell, L. 2017. The Rise of State Preemption Laws in Response to Local Policy Innovation. Publius 47(3): 403-425.

Schneider, A.L., H. Ingram, and P. deLeon. 2014. Democratic Policy Design: Social Construction of Target Populations. In Theories of the Policy Process, $3^{\text {rd }}$ ed. edited by P.A. Sabatier and C.M. Weible, 105-50. Boulder, CO: Westview.

Shipan, C., and C. M. Volden. 2005. Diffusion, Preemption, and Venue Shopping: The Spread of Local Antismoking Policies. Scholars in Health Policy Research Program Working Papers Series-31. Princeton, NJ: Robert Wood Johnson Foundation.

Shipan, C. R., and C. Volden. 2006. Bottom-up Federalism: The Diffusion of Antismoking Policies from US Cities to States. American Journal of Political Science 50(4): 825-43.

Shipan, C. R., and C. Volden. 2008. The Mechanisms of Policy Diffusion. American Journal of Political Science 52(4): 840-57.

Shipan, C. R., and C. Volden. 2012. Policy Diffusion: Seven Lessons for Scholars and Practitioners. Public Administration Review 72(6): 788-96.

Shor, B. and N. McCarty. 2011. The Ideological Mapping of American Legislatures. American Political Science Review 105(3): 530-51.

Smith, K. and C. Larimer. 2009. The Public Policy Theory Primer. Boulder, CO: Westview.

Stazyk, E.C. and H.T. Goerdel. 2011. The Benefits of Bureaucracy: Public Managers' Perceptions of Political Support, Goal Ambiguity, and Organizational Effectiveness. Journal of Public Administration Research \& Theory 21(4): 645-72.

Travis, R. and N. Zahariadis. 2002. A Multiple Streams Model of U.S. Foreign Aid Policy.” Policy Studies Journal 30(4): 495-514.

U.S. Bureau of Economic Analysis (BEA). 2017. Regional Data. http://www.bea.gov/iTable/i Table.cfm?reqid=70\&step=1\&isuri=1\&acrdn=3\#reqid=70\&step=1\&isuri=1 [Retrieved February 1, 2017].

U.S. Census Bureau. 2017. American Fact Finder: Download Center. https://factfinder.census. gov/faces/nav/jsf/pages/download_center.xhtml\# [Retrieved February 1, 2017]. 
This is an author-produced, peer-reviewed version of this article. The final, definitive version of this document can be found online at Public Works Management \& Policy, published by SAGE. Copyright restrictions may apply. doi: 10.1177/1087724X19834563

U.S. Environmental Protection Agency (EPA). 2017a. Air Data. http://www3.epa.gov/airdata/ [Retrieved February $1,2017]$.

U.S. Environmental Protection Agency (EPA). 2017b. Air Quality Index. http://airnow.gov/ index.cfm?action=aqibasics.aqi [Retrieved February 1, 2017].

Vittinghoff, E. and C.E. McCulloch. 2007. Relaxing the Rule of Ten Events per Variable in Logistic and Cox Regression. American Journal of Epidemiology 165(6): 710-718.

Walker, R. M. 2006. Innovation Type and Diffusion: An Empirical Analysis of Local Government. Public Administration 84(2): 311-35.

Weiland, P.S. 2000. Federal and State Preemption of Environmental Law: A Critical Analysis. Harvard Environmental Law Review 24(1): 237-87.

Woods, N.D., and M. Potoski. 2010. Environmental Federalism Revisited: Second-Order Devolution in Air Quality Regulation. Review of Policy Research 27(6): 721-39.

Zahariadis, N. 2014. Ambiguity and Multiple Streams. In Theories of the Policy Process, $3^{\text {rd }}$ ed. edited by P.A. Sabatier and C.M. Weible, 25-58. Boulder, CO: Westview. 